\title{
Screening of PHA-Producing Bacteria Using Bio- diesel-Derived Waste Glycerol as a Sole Carbon Source
}

\author{
Jantima TEEKA*, Tsuyoshi IMAI*, Xuehang CHENG*, Alissara REUNGSANG*****, \\ Takaya HIGUCHI*, Koichi YAMAMOTO*, Masahiko SEKINE* \\ *Division of Environmental Science and Engineering, Graduate School of Science and \\ Engineering, Yamaguchi University, Yamaguchi 755-8611, Japan \\ **Department of Biotechnology, Faculty of Technology, Khon Kaen University, Khon Kaen \\ 40002, Thailand \\ ***Fermentation Research Center for Value Added Agricultural Products, Khon Kaen University, \\ Khon Kaen 40002, Thailand
}

\begin{abstract}
Different sources of wastewater and soil were used to screen for PHA-producing bacteria using biodiesel-derived waste glycerol as a sole carbon source by the Nile red staining method together with polymer determination. Twelve out of twenty-six isolates from biodiesel-contaminated wastewater consortium were screened for their PHA accumulation ability by cultivation in mineral salt medium supplemented with waste glycerol. The AIK7 isolate was chosen as a potential PHA producer. The PHA production on waste glycerol was examined using pure glycerol as a control substrate. The PHA content of AIK7 isolate cultivated in $10 \mathrm{~g} / \mathrm{L}$ glycerol could reach $35 \%$ cell dry weight in 72 hours from waste glycerol and 33\% cell dry weight in 120 hours from pure glycerol cultivation. It can be seen that at this content of waste glycerol, AIK7 isolate is effectively capable of biotransforming glycerol into polymer from low-grade glycerol.
\end{abstract}

Keywords: biodiesel, isolation, polyhydroxyalkanoates (PHA), waste glycerol.

\section{INTRODUCTION}

Polyhydroxyalkanoic acids (PHA) are intracellular granules that are normally found in prokaryotes. The biosynthesis and accumulation of PHA are common phenomena in approximately 300 different microorganisms (Lee, 1996a). Usually, bacteria enter into the PHA accumulation phase when a growth-limiting condition has occurred by the depletion of an essential component such as nitrogen, phosphorus, sulfur and oxygen in the presence of excess carbon source (Anderson and Dawes, 1990; Lee, 1996b). Polyhydroxyalkanoic acids act as a form of carbon and energy reserve (Dawes and Senior, 1973) or as an electron sink (Page and Knosp, 1989). Polyhydroxyalkanoic acids are materials of interest because they have some properties similar to polypropylene. They can completely degrade in the environment because of their very short half-life and they can be produced from renewable resources (Madison and Huisman, 1999; Shimao, 2001). Compared to conventional petroleum-based plastics, PHAs have a smaller environmental effect and a reduced reliance on nonrenewable fossil fuels (Akiyama et al., 2003). They can also be used in many fields, and new potential applications are still emerging (Philip et al., 2007). Nevertheless, the production of biodegradable plastics on a large scale is limited mainly because of the relative expense of the substrate. It has been estimated that substrate costs account for about $40 \%$ of the total PHA production costs (Choi and Lee, 1997) and makes the difference in price of poly-3-hydroxybutyrate (P3HB) from Biomer about 12 times the cost of polypropylene (Castilho et al., 2009).

Address correspondence to Tsuyoshi Imai, Division of Environmental Science and Engineering, Yamaguchi University, Email: imai@yamaguchi-u.ac.jp

Received June 9, 2010, Accepted September 10, 2010.

$$
\text { - } 373 \text { - }
$$


Biodiesel, one of the best choices among alternative fuels has the potential to completely displace its petroleum counterpart (Johnson and Taconi, 2007). Thailand biodiesel development strategy is to increase the production capacity from 365 million liters in 2007 to 3100 million liters by 2012 (Siriwardhana et al., 2009). It is estimated that about 250 million kilograms of waste glycerol byproduct will be produced annually. The byproduct composition, in addition to glycerol, varies from plant to plant depending on biodiesel feedstock. In general, it contains methanol and soap as two major impurities with various elements such as sodium, potassium, phosphorus, magnesium, sulfur, calcium (Pyle et al., 2008), carbon, nitrogen, glycerides, fatty acid soaps (FFA) and fatty acid methyl ester (FAME) (Ashby et al., 2004; Thompson and He, 2006). Thompson and He (2006) analyzed the waste vegetable oil (WVO) feedstock used in the biodiesel transesterification process and found that the WVO feedstock contained $18.8 \mathrm{wt} \%$ palmitic, $6.3 \mathrm{wt} \%$ stearic, $40.5 \mathrm{wt} \%$ oleic, $28 \mathrm{wt} \%$ linoleic and 1.5 $\mathrm{wt} \%$ linolenic acids. The demand for these byproducts in the glycerol market was limited by their impurities (Johnson and Taconi, 2007) because the purification cost is imperative before using them in other industries. The excess glycerol generated may become an environmental problem, since it cannot be disposed of in the environment (G. P. da Silva et al., 2009).

Recently, much work has been done using biodiesel-derived waste glycerol for PHA production by Cupriavidus necator JMP134, Paracoccus denitrificans (Mothes et al., 2007), Cupriavidus necator DSM 545 (Cavalheiro et al., 2009), Bacillus sonorensis, Halomonas hydrothermalis (Shrivastav et al., 2010), Halomonas sp. KM-1 (Kawata and Aiba, 2010), osmophilic organism (Koller et al., 2005), Pseudomonas oleovorans NRRL B-14682 and Pseudomonas corrugata 388 (Ashby et al., 2004) from different sources of biodiesel feedstock. Among these, in small scale cultivation, $H$. hydrothermalis could accumulate PHB content up to $75.8 \%$ of the cell dry weight (CDW) with $3 \mathrm{~g} / \mathrm{L}$ PHB concentration by using mineral salt medium (MSM) supplemented with $2 \%(\mathrm{w} / \mathrm{v})$ of $95 \%$ glycerol content from Jatropha biodiesel byproduct (Shrivastav et al., 2010)

In Thailand, as the biodiesel industry grows, research study for biodiesel-derived waste glycerol conversion into useful product should be done in order to minimize the environmental problem caused by this waste stream. This gives way to ascertain PHA-producing organisms from this unpurified carbon source.

\section{MATERIALS AND METHODS Materials}

Waste vegetable oil-based biodiesel-derived waste glycerol (WG) with 50\% purity was kindly provided by Assoc. Prof. Dr. Alissara Reungsang. Different sources of microorganisms from domestic wastewater, biodiesel-contaminated wastewater, sewage and biodiesel-contaminated soil were designated as WW1, WW2, WW3 and Soil, respectively. All bacterial sources were collected from Khon Kaen Province, Thailand. Each liter of MSM contained $6.7 \mathrm{~g}$ of $\mathrm{Na}_{2} \mathrm{HPO}_{4} \cdot 7 \mathrm{H}_{2} \mathrm{O}, 1.5 \mathrm{~g}$ of $\mathrm{KH}_{2} \mathrm{PO}_{4}, 1.0 \mathrm{~g}$ of $\left(\mathrm{NH}_{4}\right)_{2} \mathrm{SO}_{4}, 0.2 \mathrm{~g}$ of $\mathrm{MgSO}_{4} \cdot 7 \mathrm{H}_{2} \mathrm{O}, 60 \mathrm{mg}$ of ferrous ammonium citrate, $10 \mathrm{mg}$ of $\mathrm{CaCl}_{2} \cdot 2 \mathrm{H}_{2} \mathrm{O}$, and $1 \mathrm{~mL}$ of trace-element solution. Each liter of trace-element solution contained $0.3 \mathrm{~g}$ of $\mathrm{H}_{3} \mathrm{BO}_{3}, 0.2 \mathrm{~g}$ of $\mathrm{CoCl}_{2} \cdot 6 \mathrm{H}_{2} \mathrm{O}, 0.1 \mathrm{~g}$ of $\mathrm{ZnSO}_{4} \cdot 7 \mathrm{H}_{2} \mathrm{O}, 30 \mathrm{mg}$ of 
$\mathrm{MnCl}_{2} \cdot 4 \mathrm{H}_{2} \mathrm{O}, 30 \mathrm{mg}$ of $\mathrm{NaMoO}_{4} \cdot 2 \mathrm{H}_{2} \mathrm{O}, 20 \mathrm{mg}$ of $\mathrm{NiCl}_{2} \cdot 6 \mathrm{H}_{2} \mathrm{O}$, and $10 \mathrm{mg}$ of $\mathrm{CuSO}_{4} \cdot 5 \mathrm{H}_{2} \mathrm{O}$ (Ramsay et al., 1990). Nile red solution $0.025 \%(\mathrm{w} / \mathrm{v})$ was prepared in dimethylsulfoxide (DMSO).

\section{Quantitative analysis of PHA}

Extraction and estimation of PHA were performed according to Shi et al. (1997) modified method as follows: one milliliter cell was centrifuged and resuspended in 0.5 $\mathrm{mL}$ sodium hypochlorite solution and then incubated in a water bath at $37^{\circ} \mathrm{C}$ for 1 hour. The lysed cell pellet was centrifuged and then successively washed with water, acetone, and alcohol. One milliliter of chloroform was added and incubated at $65^{\circ} \mathrm{C}$ for 2 hours. Chloroform solution of $0.1-0.5 \mathrm{~mL}$ volume was transferred to a clean test tube, was evaporated and then $5 \mathrm{~mL}$ of concentrated sulfuric acid was added. The sample was boiled for 10 minutes. An absorbance measurement was made at $235 \mathrm{~nm}$ using a UV-spectrophotometer against concentrated sulfuric acid.

\section{Free glycerol determination}

Substrate utilization was measured by the Bondioli and Della Bella (2005) method. The working reagents prepared for the experiment were $1.6 \mathrm{M}$ acetic acid stock solution and 4.0 $\mathrm{M}$ ammonium acetate stock solution. The $0.2 \mathrm{M}$ Acetylacetone solution and $10 \mathrm{mM}$ sodium periodate solution were prepared in 1:1 ratio of acetic acid stock solution and ammonium acetate stock solution. Extraction solvent or working solvent was prepared by mixing an equal volume of distilled water with $95 \%$ ethanol. A mixture of hexane and extraction solvent was added to the sample. Upon mixing, two layers were formed and the lower layer was transferred into a new test tube. Then, $1.5 \mathrm{~mL}$ of the working solvent and $1.2 \mathrm{~mL}$ of sodium periodate were added. Afterwards, $1.2 \mathrm{~mL}$ of acetylacetone solution was added and the mixture was placed in a water bath at $70^{\circ} \mathrm{C}$ for $1 \mathrm{~min}$. An absorbance measurement was made at $410 \mathrm{~nm}$ against a blank sample.

\section{Batch culture}

The experiment was carried out in a batch culture using wastewater and soil as inoculum. Bacterial source was pre-grown in nutrient broth (NB) for 24 hours and 5\% of inoculum was inoculated in MSM supplemented with 5\% (w/v) of WG with an initial $\mathrm{pH}$ of 7. Aerobic condition was maintained by shaking at $30^{\circ} \mathrm{C}$ and $150 \mathrm{rpm}$. Fluorescence of lipid-accumulating bacteria was determined on MSM agar supplemented with $2 \%(\mathrm{w} / \mathrm{v}) \mathrm{WG}$ containing $0.5 \mu \mathrm{g} / \mathrm{mL}$ Nile red. Viable culture was directly exposed to ultraviolet light monitoring fluorescent emission compared to a control, i.e. a negative plate without microbial culture. Gram staining was done with twelve selected isolates. The best selected isolate was pre-grown on nutrient agar (NA) and was inoculated in NB for 24 hours. Five percent of inoculum was inoculated into MSM supplemented with $10 \mathrm{~g} / \mathrm{L}$ glycerol concentration of WG or pure glycerol (PG) with an initial $\mathrm{pH}$ of 7 . Samples were taken for protein assay by the Lowry method, PHA determination and chemical oxygen demand (COD) analysis by standard methods. Total nitrogen and total phosphorus analyses were done by following the standard methods for the examination of sewage wastewater (Japan Sewage Works Association, 1997). Sodium element was determined by inductively coupled plasma-atomic emission spectrometry (ICP-AES) (Optima 3300 DV, Perkin Elmer, USA). 


\section{RESULTS AND DISCUSSION}

Screening of the potential source of PHA-producing bacteria using waste glycerol as carbon source

In order to screen the potential source of PHA-producer from four kinds of microbial sources, bacterial cultivation in MSM supplemented with $5 \%(\mathrm{w} / \mathrm{v})$ of WG together with fluorescence investigation of lipid-accumulating consortium were examined. It was found that all bacterial consortiums spread on MSM agar supplemented with $2 \%(\mathrm{w} / \mathrm{v})$ WG containing Nile red showed weak yellow fluorescence under long wavelength ultraviolet irradiation (Fig. 1).

A lipophilic dye, Nile red stains not only PHA but also many kinds of lipids. Spiekermann et al. (1999) proved that triacylglycerols (TAG) accumulated strain Acinetobacter calcoaceticus could exhibit a bright fluorescence when grown on mineral salt medium in the presence of $0.5 \mu \mathrm{g} / \mathrm{mL}$ Nile red. In this study, polymer determination was done as a confirmation method. Results showed that at 96 hours, PHA content of WW2 consortium culture reached 33\% CDW with overall 53\% soluble COD (SCOD) removal whereas Soil consortium reached 15\% CDW and showed 56\% SCOD removal efficiency (Fig. 2). The result of PHA content indicated that WW2 consortium contained highly potential PHA-producer.

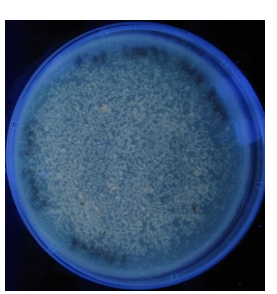

(a)

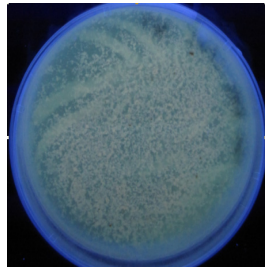

(b)

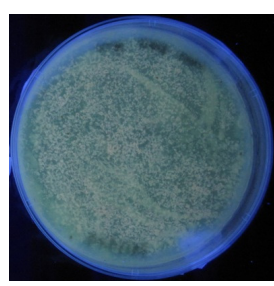

(c)

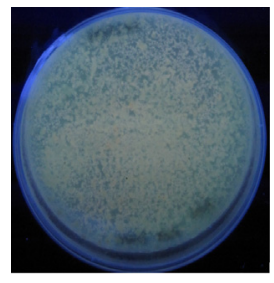

(d)

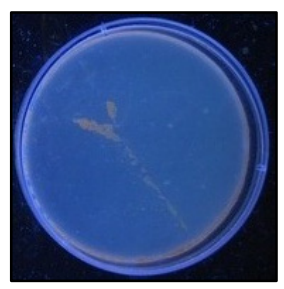

(e)

Fig. 1 - Fluorescence of three-day incubation of viable WW1 (a) WW2 (b) WW3 (c) soil (d) and negative control plate (e) incubated at $30^{\circ} \mathrm{C}$ illuminated with long wavelength ultraviolet

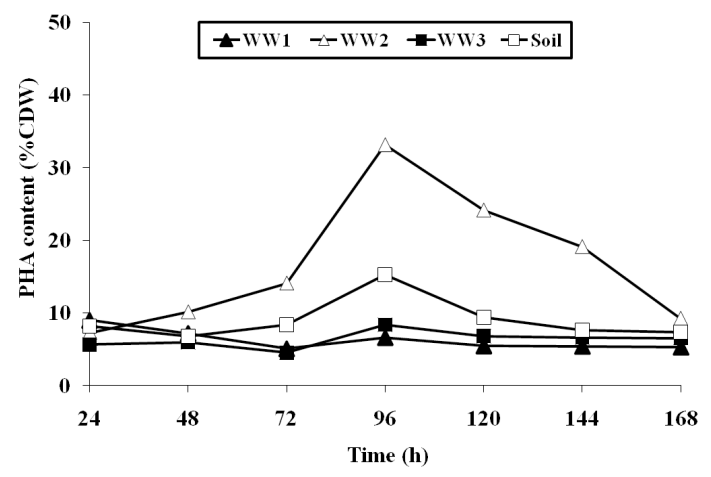

(a)

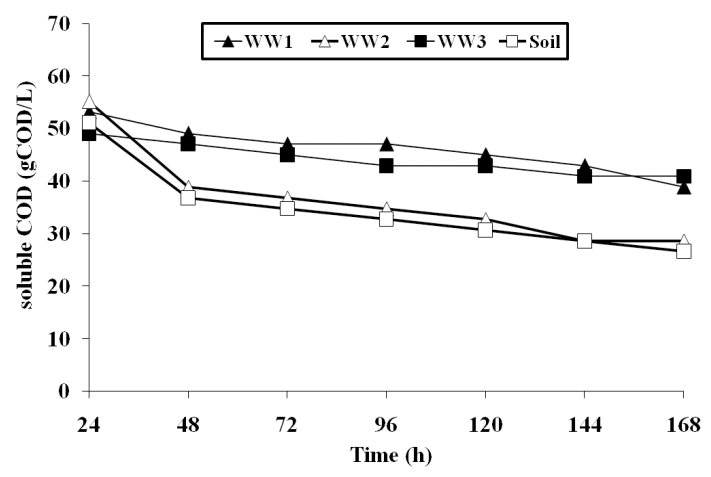

(b)

Fig. 2 - PHA content (a) and soluble COD (b) from four consortiums cultivated in MSM supplemented with $5 \%(\mathrm{w} / \mathrm{v}) \mathrm{WG}$ under aerobic condition at $150 \mathrm{rpm}$ and $30^{\circ} \mathrm{C}$ 


\section{Isolation of PHA-producing bacteria}

Bacterial isolation was done by ten-fold dilution of seven-day-old culture of wastewater consortium spread on NA plates. Twenty six bacterial isolates of different morphology colonies were obtained from WW2 consortium. They were then preliminarily selected by Nile red staining. Twelve selected isolates, appearing as gram-negative, were further examined for their own PHA production ability. PHA biosynthesis of twelve isolates was individually investigated by batch culture in MSM supplemented with 5\% (w/v) WG. PHA concentrations from AIK6, AIK7, AIK11 and AIK16 isolates were 219, 662, 330 and $263 \mathrm{mg} / \mathrm{L}$ respectively, indicating that all four isolates could utilize and efficiently biotransform WG into PHA inside their cell better than others (Table 1). When colonies of AIK 7 and AIK11 isolates were grown in the presence of Nile red, their cells exhibited a bright yellow fluorescence on the first three days of cultivation as described by Spiekermann et al. (1999) and then fluorescence intensity decreased relative to the amount of lipid polymer inside their cell. Among twelve isolates, AIK7 isolate was chosen as a highly potential PHA-producing strain for further experiment.

\section{PHA production on pure glycerol (PG) and waste glycerol (WG)}

PHA production efficiency of AIK7 isolate on WG was examined by using PG as a control substrate at $10 \mathrm{~g} / \mathrm{L}$ of glycerol concentration. Nutrient analysis of MSM containing $10 \mathrm{~g} / \mathrm{L}$ glycerol showed that the medium contained $1.44 \mathrm{~g} / \mathrm{L}$ and $1.25 \mathrm{~g} / \mathrm{L}$ of total nitrogen, and 1.28 and $1.26 \mathrm{~g} / \mathrm{L}$ of total phosphorus in $\mathrm{WG}$ and PG medium, respectively. It was interesting to find that when WG was used as carbon source, PHA production could reach to $1.22 \mathrm{~g} / \mathrm{L}$ in 84 hours which was higher than $0.85 \mathrm{~g} / \mathrm{L}$ in 120 hours when PG was used (Fig. 3a). The PHA content of AIK7 isolate cultivated in WG reached to $35 \%$ in 72 hours whereas in $\mathrm{PG}$ cultivation the highest concentration was $33 \%$ in 120 hours (Fig. 3b). Optimum $\mathrm{pH}$ for PHA accumulation in this condition was 6 - 6.5 (data not shown). The viable colony number of WG cultivation of $6.8 \times 10^{8}$ $\mathrm{cfu} / \mathrm{mL}$ in 36 hours indicated that AIK 7 isolate is able to grow well in this glycerol content. The maximum product yield coefficient 0.22 and 0.09 (g PHA/g glycerol) were attained from WG and PG, respectively. At the end of cultivation, glycerol content in

Table 1- Result summary of twelve isolates from WW2 cultivated in MSM supplemented with $5 \%(\mathrm{w} / \mathrm{v}) \mathrm{WG}$

\begin{tabular}{cccc}
\hline Isolate & $\begin{array}{c}\text { PHA } \\
\text { concentration } \\
(\mathrm{mg} / \mathrm{L})\end{array}$ & $\begin{array}{c}\text { SCOD } \\
\text { removal }(\%)\end{array}$ & $\begin{array}{c}\text { g PHA/ } \\
\text { g COD } \\
\text { consumed }\end{array}$ \\
\hline AIK3 & 113 & 23.18 & 0.008 \\
AIK4 & 117 & 9.82 & 0.020 \\
AIK6 & 219 & 16.50 & 0.022 \\
AIK7 & 662 & 19.84 & 0.055 \\
AIK10 & 150 & 19.84 & 0.012 \\
AIK11 & 330 & 12.48 & 0.043 \\
AIK12 & 116 & 13.16 & 0.014 \\
AIK15 & 109 & 8.14 & 0.022 \\
AIK16 & 263 & 13.16 & 0.033 \\
AIK17 & 108 & 6.48 & 0.027 \\
AIK21 & 112 & 26.52 & 0.007 \\
AIK22 & 126 & 26.52 & 0.008 \\
\hline
\end{tabular}


each culture medium was almost depleted (Fig. 3c) whereas SCOD removal was $50 \%$ in WG and $80 \%$ in PG (data not shown). It can be seen that AIK7 isolate not only can utilize glycerol but also has high capability for waste utilization. However, in this experiment, it was observed that AIK7 isolate could not grow well when a higher concentration of WG (25 g/L glycerol) was applied. It also made the colony characteristics change from the original form. This worse effect may be caused by a very high COD (approximately $60 \mathrm{~g} \mathrm{COD} / \mathrm{L}$ ) contained in the medium.

Several researchers have reported that the growth and product formation of microorganisms cultivated in biodiesel-derived WG were inhibited resulting from sodium salt and other impurities in WG (Johnson and Taconi, 2007; Mothes et al., 2007; Cavalheiro et al., 2009). In the present study, WG pretreatment was done to remove the residual methanol. Mothes et al. (2007) concluded that the sodium quantity which caused PHB biosynthesis reduction is greater than $5 \mathrm{~g} / \mathrm{L}$. ICP-AES analysis showed that MSM supplemented with WG contained $1.384 \mathrm{~g} / \mathrm{L}$ sodium. Therefore, this quantity should not inhibit bacterial growth or polymer production.

The results in Table 2 show that, at 72 hours of cultivation, AIK7 isolate cultivated in WG consumed less glycerol substrate while growing and accumulating PHA much better than in PG cultivation. Ashby et al. (2004) studied the PHA production from biodiesel co-product stream (CSBP) by P.oleovorans and P.corrugata, and they found that the carbon source utilization patterns for both strains were slightly different. They

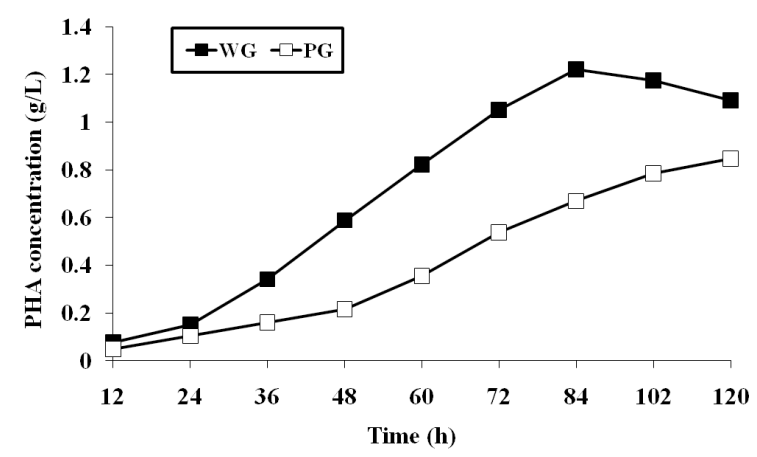

(a)

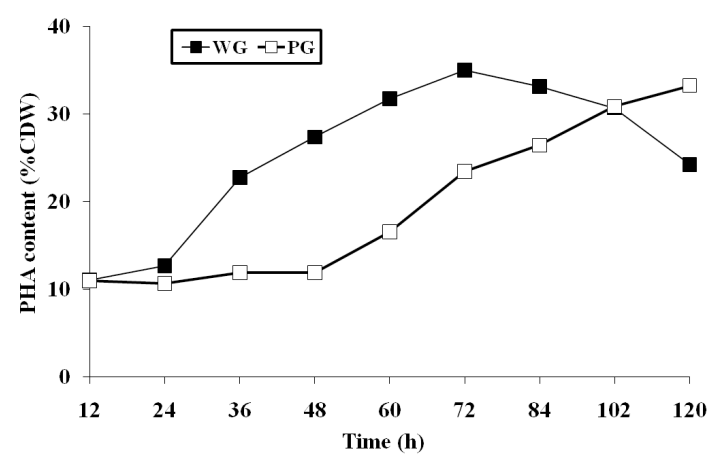

(b)

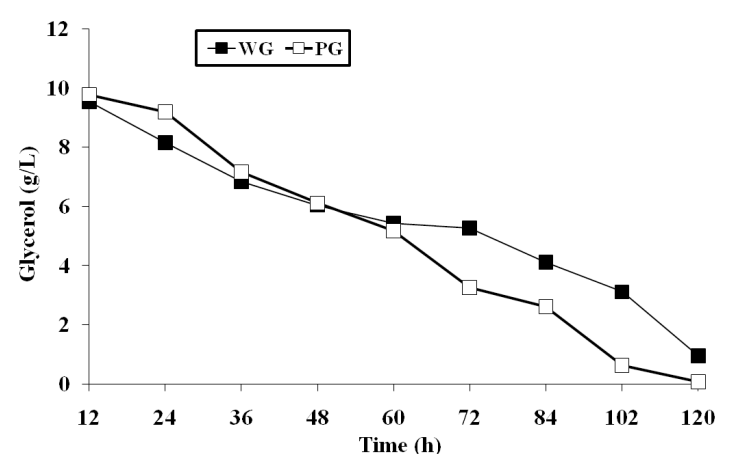

(c)

Fig. 3 - PHA concentration (a) PHA content (b) and residual glycerol (c) of AIK7 isolate cultivated in MSM supplemented with $10 \mathrm{~g} / \mathrm{L}$ glycerol 
Table 2- Result summary of AIK7 isolate cultivated in MSM supplemented with $10 \mathrm{~g} / \mathrm{L}$ glycerol at 72 hours

\begin{tabular}{lccccccc}
\hline $\begin{array}{l}\text { Carbon } \\
\text { source }\end{array}$ & $\begin{array}{c}\text { PHA } \\
(\mathrm{g} / \mathrm{L})\end{array}$ & $\begin{array}{c}\text { cell dry } \\
\text { weight } \\
(\mathrm{g} / \mathrm{L})\end{array}$ & $\begin{array}{c}\text { PHA } \\
\text { content } \\
(\% \mathrm{CDW})\end{array}$ & $\begin{array}{c}\text { substrate } \\
\text { consumed } \\
(\mathrm{g} / \mathrm{L})\end{array}$ & $\begin{array}{c}\text { initial } \\
\mathrm{COD} \\
(\mathrm{g} / \mathrm{L})\end{array}$ & $\begin{array}{c}\text { COD } \\
\text { consumed } \\
(\mathrm{g} / \mathrm{L})\end{array}$ & $\begin{array}{c}\text { SCOD } \\
\text { removal } \\
(\%)\end{array}$ \\
\hline $\begin{array}{l}\text { Waste } \\
\text { glycerol }\end{array}$ & 1.05 & 3.01 & 35.00 & 4.74 & 27.50 & 7.01 & 25.50 \\
\hline $\begin{array}{l}\text { Pure } \\
\text { glycerol }\end{array}$ & 0.54 & 2.30 & 23.50 & 6.75 & 16.00 & 9.05 & 56.55 \\
\hline
\end{tabular}

explained that glycerol could be used as a growth substrate while the FFA and FAME, also contained in CSBP, could undergo $\beta$-oxidation to form the precursor of PHA biosynthesis. From the results obtained in this study, it might be speculated that AIK7 isolate is capable of using FFA or FAME which might reside in waste glycerol for polymer biosynthesis. Compared to PG cultivation, the medium contained only one kind of carbon source which must be used for growth and polymer biosynthesis. This could be the reason why a higher maximum yield coefficient and a higher PHA concentration were obtained in WG cultivation.

There are many factors affecting PHA production cost and they include carbon substrate cost, product yield, and the product recovery method (Choi and Lee, 1999). The cost of the substrate accounts for about $40 \%$ of the total PHA production cost (Choi and Lee, 1997). The cost of glucose, the most commonly used substrate, is about $\$ 0.23 / \mathrm{lb}$ $(\$ 0.50 / \mathrm{kg})$ (Choi and Lee, 1999). Johnson and Taconi (2007) mentioned that the market price of WG has fallen to about $\$ 0.05 / \mathrm{lb}(\$ 0.011 / \mathrm{kg})$. Considering only the effect of substrate cost, we see that the PHA production cost could be significantly reduced by using WG as the substrate as compared to glucose. The PHA production process efficiency using AIK7 isolate is low compared to a well-developed process. However, the use of AIK7 to convert abundant waste streams into higher value products could help to overcome the cost to refine these streams into higher grade glycerol or the cost associated with their discharge to the environment. The development of an efficient process using AIK7 isolate will be investigated further to decrease the overall economics of PHA production.

\section{CONCLUSIONS}

Waste glycerol from the biodiesel process is an excellent carbon source for PHA production. It is a byproduct from sustainable process, has low market price and contains a high amount of glycerol substrate for bacterial growth and PHA biosynthesis. Our prospective study to investigate biodiesel-derived waste glycerol utilization would lower the bioplastic production cost by using unpurified cheap carbon source concomitantly with harnessing disposed waste glycerol. From this research, it can be concluded that AIK7 isolate could be a good candidate as a PHA producer by using this low-grade waste glycerol as a sole carbon source.

\section{REFERENCES}

Anderson A. J. and Dawes E. A. (1990). Occurrence, metabolism, metabolic role and 
industrial uses of bacterial PHA, Micro. Biol. Rev., 54, 450-472.

Akiyama M., Tsuge T. and Doi Y. (2003). Environmental Life Cycle Comparison of Polyhydroxyalkanoates Produced from Renewable Carbon Resources by Bacterial Fermentation, Polym. Degrad. Stabil., 80(1), 183-194.

Ashby R. D., Solaiman D. K. Y. and Foglia T. A. (2004). Bacterial Poly(hydroxyalkanoate) Polymer production from the Biodiesel co-product Stream, J. Polym. Environ., 12, 105-112.

Bondioli P. and Della Bella L. (2005). An alternative spectrophotometric method for the determination of free glycerol in biodiesel, Eur. J. Lipid Sci. Technol., 107, 153-157.

Castilho L. R., Mitchell D. A. and Freire D. M. G. (2009). Production of Polyhydroxyalkanoates (PHAs) from waste materials and by-product by submerged and solid-state fermentation, Bioresource Technology, 100, 5996-6009.

Cavalheiro J. M. B. T., M. Catarina M. D. de Almeida, Christian G. and da Fonseca M. M. R. (2009). Poly(3-hydroxybutyrate) production by Cupriavidus necator using waste glycerol, Process Biochemistry, 44, 509-515.

Choi J. and Lee S. Y. (1997). Process analysis and economic evaluation for poly(3-hydroxybutyrate) production by fermentation, Bioprocess Eng., 17, 335-342.

Choi J. and Lee S. Y. (1999). Factors affecting the economics of polyhydroxyalkanoates production by bacterial fermentation, Appl. Microbiol. Biotechnol., 51, 13-21.

da Silva G.P., Mack M. and Contiero J. (2009). Glycerol: A promising and abundant carbon source for industrial microbiology, Biotechnology Advances, 27, 30-39.

Dawes E. A. and Senior P. J. (1973). The role and regulation of energy reserve polymers in microorganisms, Adv. Microb. Physiol., 10, 203-253.

Johnson D. T. and Taconi K. A. (2007). The Glycerin Glut: Options for the Value-Added Conversion of Crude Glycerol Resulting from Biodiesel Production, Environmental Progress, 26(4), 338-348.

Kawata Y. and Aiba S. (2010). Poly(3-hydroxybutyrate) Production by Isolated Halomonas sp. KM-1 Using Waste Glycerol, BioSci. Biotechnol. Biochem., 74(1) 175-177.

Koller M., Bona R., Braunegg G., Hermann C., Horvat P., Kroutil M., Martinz J., Neto J., Pereira L. and Varila P. (2005). Production of Polyhydroxyalkanotes from Agricultural Waste and Surplus Materials, Biomacromolecules, 6, 561-565.

Lee S. Y. (1996a). Review Bacterial Polyhydroxyalkanoates, Biotechnol. and Bioeng., 49, $1-14$.

Lee S. Y. (1996b). Plastic bacteria? Progress and prospects for polyhydroxyalkanoate production in bacteria, Trends in Biotechnology, 14, 431-438.

Madison L. L. and Huisman G. W. (1999). Metabolic engineering of poly(3-hydroxy alkanoates): from DNA to plastic, Microbiology and Molecular Biology Reviews, 63, 21-53.

Mothes G., Schnorpfeil C. and Ackermann J.-U. (2007). Production of PHB from crude glycerol, Eng. Life Sci., 7(5), 475-479.

Page W. J. and Knosp O. (1989). Hyperproduction of poly- $\beta$-hydroxybutyrate during exponential growth of Azotobacter vinelandii strain UWD, Appl. Environ. Microbiol., 55, 1334-1339.

Philip S., Keshavarz T. and Roy I. (2007). Polyhydroxyalkanoates: biodegradable polymers with a range of application, J. Chem. Technol. Biotechnol., 82, 233-247. 
Pyle D. J., Garcia R. A. and Wen Z. (2008). Producing Docosahexaenoic Acid (DHA)-Rich Algae from Biodiesel-Derived Crude Glycerol: Effect of Impurities on DHA Production and Algae Biomass Composition, J. Agric. Food. Chem., 56, 3933-3939.

Ramsay B. A., Lomaliza K., Chavarie C., Dube B., Batalille P. and Ramsay J. A. (1990). Production of Poly-( $\beta$-hydroxybutyric-co- $\beta$-hydroxyvaleric) Acids, Appl. and Environ. Microbiol., 56(7), 2093-2098.

Siriwardhana M., Opathella G. K. C. and Jha M. K. (2009). Bio-diesel: Initiatives, potential and prospects in Thailand : A review, Energy Policy, 37, 554-559.

Shi H., Shiraishi M. and Shimazu K. (1997). Metabolic flux analysis for biosynthesis of Poly( $\beta$-hydroxybutyric acid) in Alcaligenes eutropha from various carbon source, $J$. of Fermentation and Bioengineering, 84(6), 579-587.

Shimao M. (2001). Biodegradation of plastics. Current Opinion in Biotechnology, 12, 242-247.

Shrivastav A., Mishra S. K., Shethia B., Pancha I., Jain D. and Mishra S. (2010). Isolation of promising bacterial strains from soil and marine environment for polyhyhydroxyalkanoates (PHAs) production utilizing Jatropha biodiesel byproduct, International Journal of Biological Macromolecules, 47, 283-287.

Spiekermann P., Rehm B. H. A., Kalscheuer R., Baumeister D. and Steinbuchel A. (1999). A sensitive, viable-colony staining method using Nile red for direct screening of bacteria that accumulate polyhydroxyalkanoic acids and other lipid storage compounds, Arch. Microbiol., 171, 73-80.

Standard methods for the examination of sewage wastewater (1997). Japan Sewage Works Association (JSWA), Tokyo, Japan. (in Japanese)

Thompson J. C. and He B. B. (2006). Characterization of Crude Glycerol from Biodiesel Production from Multiple Feedstocks, Appl. Eng. Agric., 22(2), 261-265. 